\title{
A New Perspective in Comparing Injuries Caused by Short-Duration External and Internal Forces in Saphenous Vein
}

\author{
Emine Seyma Denli Yalvac, $\mathbf{M D}^{1}$ Alev Cumbul, $\mathrm{PhD}^{2}$ Ünal Uslu, $\mathrm{MD}^{3}$ Erdem Soztutar, $\mathrm{MD}^{4}$ \\ Edibe Bilisli, BS ${ }^{4}$ Naci Balak MD 5
}

Departments of ${ }^{1}$ Cardiovascular Surgery, ${ }^{3}$ Histology and Embryology, Faculty of Medicine, and ${ }^{5}$ Neurosurgery, Göztepe Education and Research Hospital, Istanbul Medeniyet University, Istanbul, Turkey; Departments of ${ }^{2}$ Histology and Embryology and ${ }^{4}$ Anatomy, Faculty of Medicine, Yeditepe University, Istanbul, Turkey

\section{ABSTRACT}

Background: Great saphenous vein (GSV) graft failure is one of the major reasons for repeat bypass grafting. A comparison of the effects of simultaneous, short-duration, externally squeezing and internally distending forces on the same segment of ex-vivo human GSV has not yet been published, although similar studies have compared the experimental injury of different ex-vivo human veins.

Methods: Approximately 8-cm-long segments of GSV were harvested from each of the 15 patients. For each specimen, one end of the vein piece was occluded at a distance of 1 $\mathrm{cm}$ with an external cross-clamp for $5 \mathrm{~min}$ and the other end was similarly occluded at a distance of $1 \mathrm{~cm}$ by an endoluminal balloon. The middle sections of the veins, which were not occluded by any means, were taken as the control group. Two histologists, who were blinded to the groups, graded the hematoxylin and eosin (H\&E) and Weigert-Van Gieson (WVG) stained sections semi-quantitatively and performed the histomorphometric measurements.

Results: The result of the histopathological evaluation of the intima layer showed that the microscopic scoring of lesions in the balloon group was significantly higher than that in the clamp and control groups $(5.16 \pm 1.32,3.83 \pm 0.75$, and $1.00 \pm 1.09$, respectively; $P<.001)$. In the adventitia layer, this level of scoring increased more in the clamp group than in the balloon and control groups $(5.16 \pm 1.16,3.00 \pm 0.89$, and 0.16 \pm 0.40 , respectively; $P<.001$ ).

Conclusion: Both the endoluminal balloon and external clamp techniques have harmful effects on the vein wall. Studying different kind of forces on different veins cannot provide us with reliable comparisons.

Received November 16 2018; received in revised form fanuary 16, 2019; accepted fanuary 18, 2019.

This study was presented in part (in abstract form) as a poster in the 18th National Anatomy Congress September 25-27, 2017, Abant, Turkey.

Correspondence: Emine Seyma Denli Yalvac, MD, Department of Cardiovascular Surgery, Göztepe Education and Research Hospital, Istanbul Medeniyet University, Kadiköy, Istanbul, Turkey; +90 2165664000 ; fax: +90 2165664000 (e-mail:seyma.denli@hotmail.com).

\section{INTRODUCTION}

Great saphenous vein (GSV) grafts are used in various revascularization surgeries, including peripheral and coronary arterial bypass and extracranial-intracranial bypass surgeries [Krayenbühl 1977; Kwok 2016; Osgood 2014; Tajima 2017; Yaşargil 1970]. The GSV has the advantage of providing high-flow revascularization even though its patency rate is lower than that of arterial grafts [Eddleman 2010; Kopjar 2016]. The GSV has a flow rate of $70-200 \mathrm{~mL} / \mathrm{min}$ and an average diameter of approximately $5 \mathrm{~mm}$ [Eddleman 2010]. However, the occlusion of the saphenous vein graft due to tissue remodeling and the narrowing of the lumen or thrombosis after surgery is a problem [Sayers 1992].

GSV graft failure is one of the major reasons for repeat coronary artery bypass grafting [Souza 2002]. It can be caused by intrinsic factors related to the vessel itself, such as perianastomotic stenosis, valvulotomy injury, and endothelial injury, or by external factors, such as hypercoagulopathy or systemic hypotension [Donaldson 1992]. If the occlusion of the vessel arises within the first month after surgery, the cause is most likely related to faulty surgical technique [Bourassa 1982; Donaldson 1992]. Technical faults account for $4 \%-25 \%$ of early failures after revascularization [Stone 2014]. In addition to the conventional open surgical technique, various other techniques (e.g., in-situ grafting, no-touch grafting, and endoscopic grafting) and some intermediate methods have been proposed to cope with the thrombotic occlusion problem [Dreifaldt 2013; Hashmi 2015; Horvath 1998; Kaplan 2013]. Unfortunately, all these surgical methods did not completely solve the problem of early or late occlusion due to the graft. Therefore, experimental studies have been conducted in various laboratory environments using animal or human vessels to understand the relationship between the GSV graft occlusion and the injuries that may have been caused by the manipulation of the GSV during the surgical harvesting technique [Cook 2004; Hashmi 2015; Johnson 2001; Meng 1999; Osgood 2014; Wise 2016; Wise 2017]. However, none of them has fully solved the pathophysiology of the GSV graft failure.

In this study, we aimed to determine the extent of a venous injury that could occur during various stages of the GSV harvesting procedures. For this purpose, we compared the injuries caused by pressure forces applied either internally or externally 
to the human saphenous venous wall for a short time. As far as we know, the comparison of the effects of simultaneous, shortduration, externally squeezing and internally distending forces on the same segment of ex-vivo human GSV has not been studied or published, although similar studies were conducted in which different ex-vivo human veins were compared in terms of experimental injuries. Studying different kinds of forces on different veins cannot provide us with reliable comparisons. Therefore, our study offers a new perspective in comparing injuries caused by short-duration external and internal forces in the saphenous vein.

\section{MATERIALS AND METHODS}

From January 2018 to March 2018, a total of 15 GSV segments from 15 consecutive patients undergoing phlebectomy for the treatment of varicose veins by the same surgeon were included in this study ( 9 males and 6 females, mean age of $51.4 \pm 6.3)$. The ethical issues for this study have been carefully considered in line with the Declaration of Helsinki [World Medical Association. 2013] and informed consent was obtained from all patients. Approximately 8-cm-long segments of GSV were harvested from each of the 15 patients. For each specimen, one end of the vein piece was occluded at a distance of $1 \mathrm{~cm}$ with an external cross-clamp (Bulldog clamp, lightweight, straight, 35 $\mathrm{mm}$, KLS Martin, Germany) for $5 \mathrm{~min}$, and the other end was similarly occluded at a distance of $1 \mathrm{~cm}$ by an endoluminal balloon (Arterial Embolectomy Catheter 6F-EFB80, maximum liquid volume: $1.25 \mathrm{~mL}$, approximate balloon diameter: $13 \mathrm{~mm}$, Lucas Medical, California, USA). The endoluminal balloon was filled with fluid with a syringe until the vein was inflated to the same dimension recorded formerly at $75 \mathrm{mmHg}$. The middle sections of the veins, which were not occluded by any means, were taken as the control group (Figure 1).

\section{Tissue Processing}

The vein samples were immersed in $10 \%$ neutral formaldehyde in $0.1 \mathrm{~mol} / \mathrm{L}$ of phosphate buffer ( $\mathrm{pH} 7.4$ ) for fixation at $4^{\circ} \mathrm{C}$. They were dehydrated in an alcohol series $(70 \%, 90 \%, 96 \%$, and 100\%), cleared in xylene, and embedded in paraffin.

\section{Histopathologic Evaluation}

Paraffin-embedded sections of $5 \mu \mathrm{m}$ thickness were obtained from the paraffin vein blocks using a rotary microtome (model RM 2245; Leica, Wetzlar, Germany). The vein sections were mounted on poly-L-lysine-coated slides, which were stained with hematoxylin and eosin (H\&E) and Weigert-Van Gieson (WVG) techniques (04-053812/L, Bio Optica, Italy), and histopathologically analyzed.

\section{Scoring}

Two histologists who were blinded to the groups graded the $\mathrm{H} \& \mathrm{E}$ and WVG stained sections semi-quantitatively. For the histologic evaluation, epithelial damage, congestion,

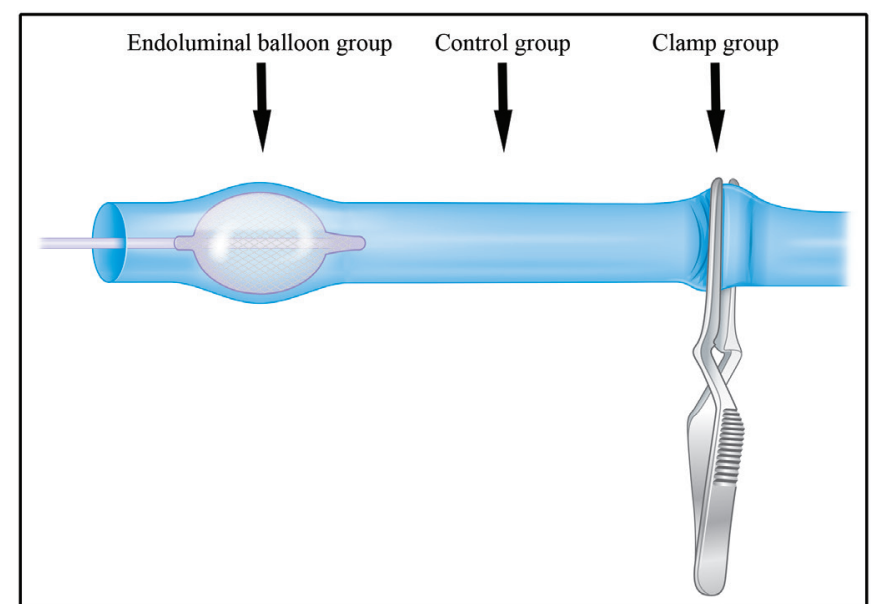

Figure 1. In each specimen, one end of the vein piece was occluded at a distance of $1 \mathrm{~cm}$ with an external cross-clamp for $5 \mathrm{~min}$ and the other end was similarly occluded at a distance of $1 \mathrm{~cm}$ by an endoluminal balloon. The middle sections of the veins, which were not occluded by any means, were taken as the control group.

inflammatory cell infiltration, and edema were interpreted in sections under the light microscope (Leica DM 6000 B microscopy system and Leica Application Suite, Leica Microsystems, Wetzlar, Germany). Sections were scored from 0 to 3 according to a grading scale, which is a modification of the semi-quantitative counting method for quantification of structures that has been previously published by Pilmane et al [Pilmane 2011] (Table). These parameters were evaluated separately for tunica intima, media, and adventitia in all sections as previously described [Karabulut 1998; Wali 2003].

\section{Histomorphometric Measurements}

Two histologists who were blinded to the groups performed all calculations. For thicknesses quantification, Stereo Investigator 11.0 (Microbrightfield, Colchester, VT, USA) was used on a computer system connected to a light microscope (DM 4000B; Leica), a CCD digital camera (Microfire 1600x1200P; Optronics, Goleta, CA), and an image capture card (FireGL Advance Micro Device, ATI, Camberley, UK). A computer-controlled motorized specimen stage (BioPrecision, Hawthorne, NY, USA) and an electronic microcator (Heidenhain, Traunreut, Germany) were used to control movement in the $\mathrm{x}, \mathrm{y}$, and $\mathrm{z}$ planes using a connected joystick. The Quick Measure Line of this system was used to determine the thicknesses of the tunica intima, media, and adventitia. Five different thicknesses were measured from each layer, and the average of these thicknesses was calculated in the H\&E stained vein sections.

\section{Statistical Analysis}

Calculations were conducted using SPSS version 22.0 for a personal computer (SPSS, Chicago, IL, USA). A one-way analysis of the variance, followed by Tukey's post hoc test for parametric values, was used for the intergroup analysis. Values of $P<.05$ were considered significant. 


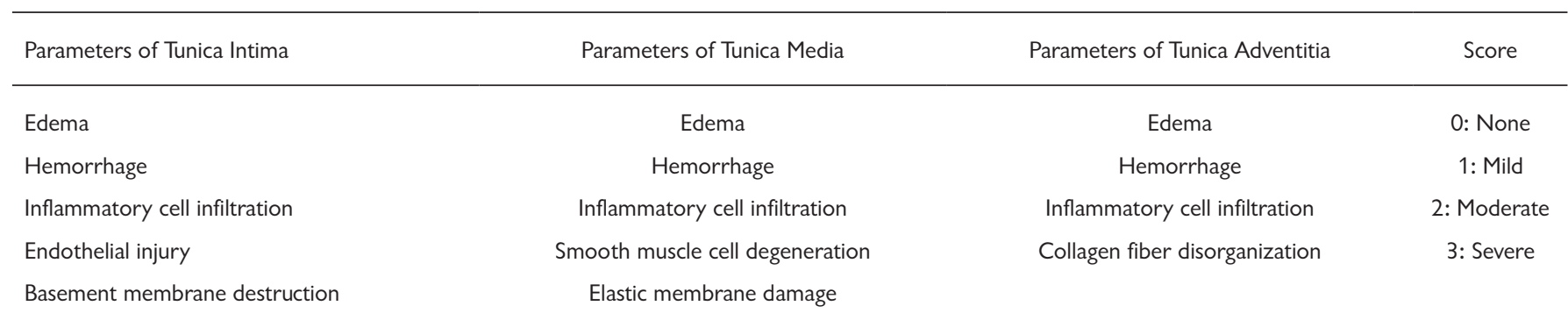

\section{RESULTS}

Cross-sections from all of the groups were analyzed for the thicknesses of the layers of the saphenous vein. The photomicrographs demonstrate the sections taken from the veins stained with the H\&E technique (Figure 2; C1-B1-CL1).

The thickness of the tunica intima was different among the control, balloon, and clamp groups. A pronounced enlargement was observed in the balloon group in comparison with the control and clamp groups $(119.2 \pm 50.93 \mu \mathrm{m}, 59.87 \pm$ $22.83 \mu \mathrm{m}$, and $61.24 \pm 12.61 \mu \mathrm{m}$, respectively; $P<.05)$. The increase in the thickness of the tunica adventitia was more significant in the external cross-clamp group $(743.6 \pm 176.5$ $\mu \mathrm{m})$ than in the balloon group $(617.6 \pm 196.4 \mu \mathrm{m} ; P<.001)$ and control group $(251.5 \pm 42.55 \mu \mathrm{m} ; P<.001)$ (Figure 2 ; top row of graphs).

Cross-sections from all of the groups were evaluated for the histopathological scores of the layers of the saphenous vein. The photomicrographs demonstrate the sections taken from the vein stained with $H \& E$ (Figure 2; C1-B1-CL1) and WVG techniques (Figure 2; C2-B2-CL2).

The result of the histopathological evaluation of the intima layer showed that the microscopic scoring of lesions in the balloon group was significantly higher than that in the clamp and control groups $(5.16 \pm 1.32,3.83 \pm 0.75$, and $1.00 \pm 1.09$, respectively; $P<.001)$. Specifically, endothelial damage and hemorrhage were evident in the H\&E and WVG staining. In the adventitia layer, this level of scoring increased more in the clamp group than in the balloon and control groups (5.16 $\pm 1.16,3.00 \pm 0.89$, and $0.16 \pm 0.40$, respectively; $P<.001$ ). Particularly, edema and elastic fiber loss were clearly visible in the WVG sections (Figure 2; bottom row of graphs).

\section{DISCUSSION}

The results of this study demonstrate that pressure forces applied to the human saphenous venous wall for a short time, either internally or externally, can be equally hazardous. The effects of externally squeezing or internally distending forces on the ex-vivo human GSV suggest that even relatively mild distending or stretching forces during GSV harvesting in an actual surgery can easily injure the vein and subsequently lead to the failure of the graft in the early or late period after surgery.

In animals, various authors have studied injury models of endovascular lesions mainly in the arteries [Gabeler 2002;
Manship 1985]. For example, balloon injury to the rat carotid artery was examined and found to cause intimal hyperplasia and to decrease lumen diameter [Perek 2016]. However, the structure of veins is different from that of arteries. The walls of veins are thinner than those of arteries and the dissection of veins in both animals and humans is more difficult than that of arteries; as a result, veins are more prone to be injured during manipulation. Endothelial injury caused by various devices, including vascular clamps and balloon and vessel loops, has been studied in rat and human veins. However, in the majority of these studies, the clamp and balloon groups used veins from different subjects. Based on these studies, it was not possible to determine the degree of similarity or difference between vascular injuries that can be caused by an internal balloon or external clamp in the same vein segment. Thus, in our study, all of the clamp-applied, balloon-applied, and control samples of veins were obtained from the same vein segment of the same patient. The situations that could arise from histological differences in the different vessels of different patients and that could affect the results of the study were eliminated. We chose to apply pressure for a short time in accordance with published animal studies demonstrating that, as the duration of pressure increased, the degree of injury increased and a complete endothelial disruption was inevitable after $30 \mathrm{~min}$ [Babin-Ebell 2010].

Similar pressure forces to the ones tested in this study occur during real surgery. During traditional graft harvesting, the GSV is frequently uncovered from its adventitial layer and inflated to eliminate spasm. These techniques may cause GSV graft injury and, later, occlusion [Souza 2002]. Animal models have shown that mechanical traumas may occur during grafting that can damage the vessel wall. Of course, there are other reasons for occlusion in the event of the failure of the GSV-grafted bypass surgery besides mechanical trauma. GSV grafts have other shortcomings, including a caliber mismatch between the donor and recipient vessels and the presence of valves that can be sites of thrombus formation [Eddleman 2010]. Additionally, vein grafts adapt to the arterial circulation naturally and intimal hyperplasia, which is the principal impediment to more durable grafts, occurs in the vein grafts [Davies 2011].

Various graft harvesting techniques, including the "notouch" harvesting technique and endoscopic GSV segment harvesting, have been developed to prevent GSV injury that can cause occlusion. However, minimally invasive endoscopic GSV segment harvesting may also have an adverse effect on 


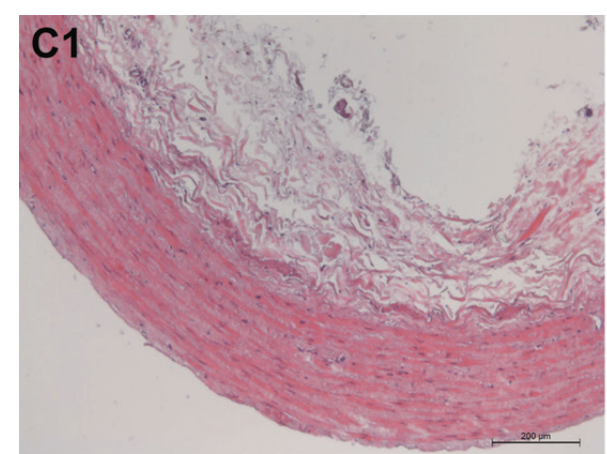

Tunica intima

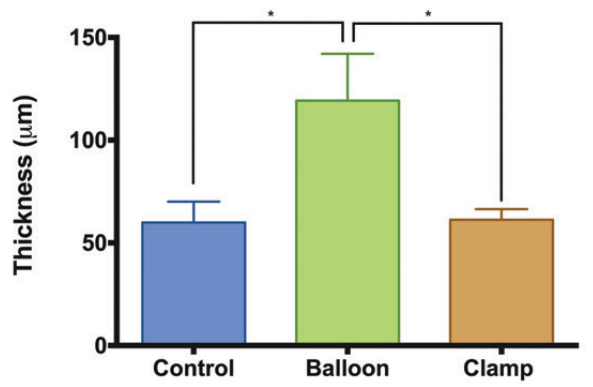

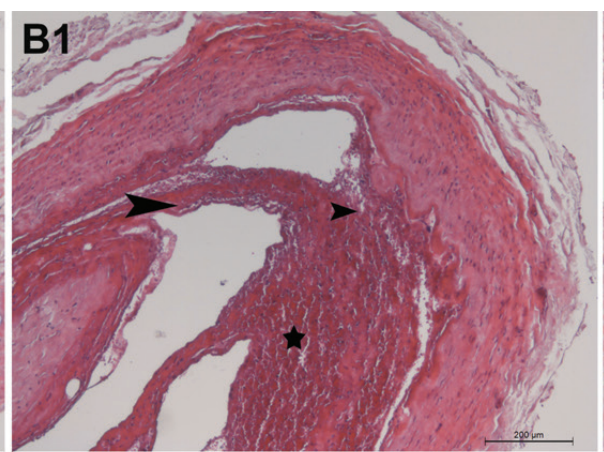

Tunica media
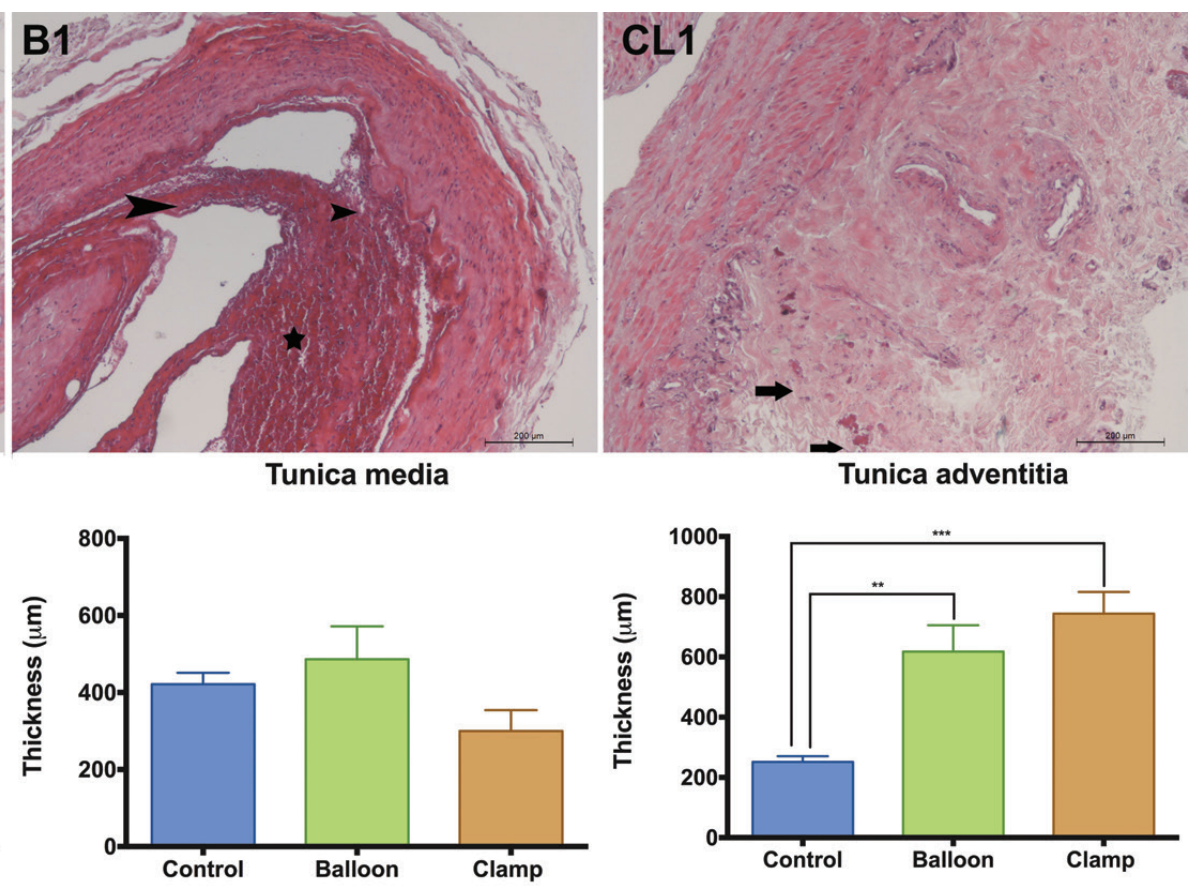

Tunica adventitia
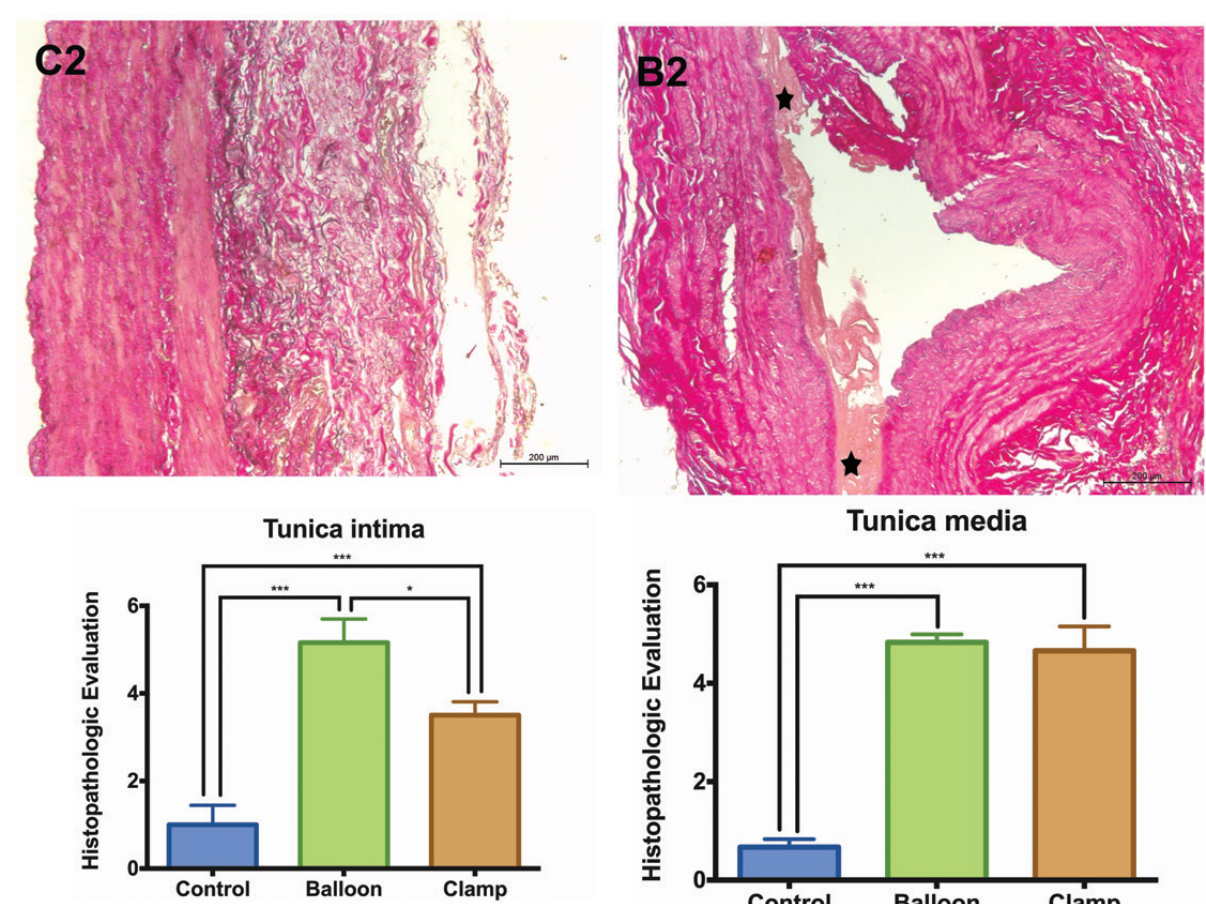

Tunica media

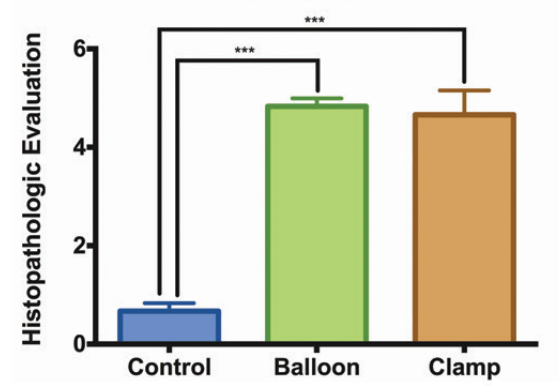

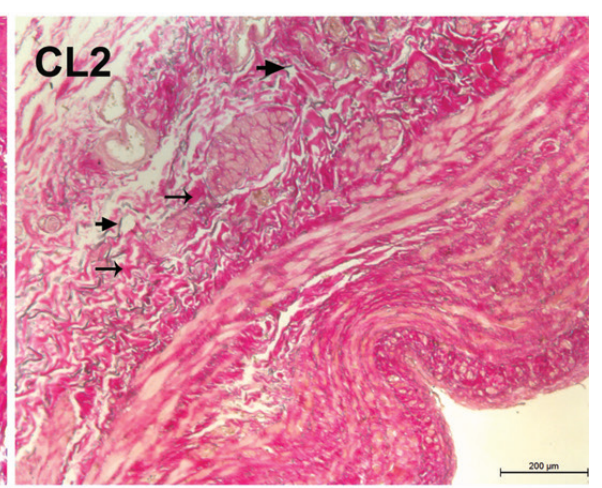

Tunica adventitia

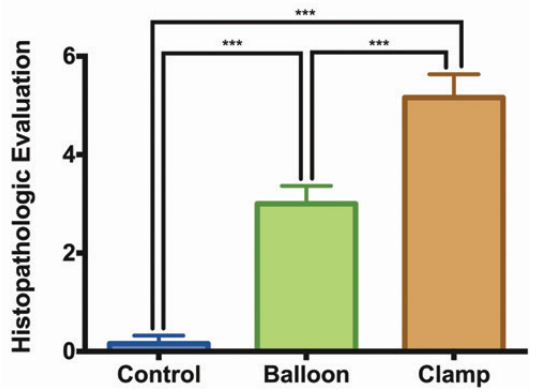

Figure 2. Photomicrographs show the histomorphometric measurements and histopathological evaluations for all groups. C1, B1, and CL1 demonstrate the H\&E staining in the tunica intima, media, and adventitia of the saphenous vein. Vascularization is indicated by a black arrowhead, hemorrhage by a star, and edema by an arrow. C2, B2, and CL2 demonstrate the WVG staining technique in the tunica intima, media, and adventitia of the saphenous vein. A hemorrhage is indicated by a star, and elastic and collagen fibers by an arrow. The magnifications of all photomicrographs are $\times 10$. The scale bars represent $200 \mu \mathrm{m}$. The first row of graphs compares the thicknesses of all the layers between the control and an experimental group. Data are presented as micrometers of the tunica intima, media, and adventitia of the saphenous vein. The second row of graphs compares the histopathological evaluations of all the layers of the saphenous vein. Data are expressed as mean $\pm \mathrm{SD}\left({ }^{*} P<.05, * * P<.01\right.$, and $\left.* * * P<.001\right)$. C indicates control; B, balloon, $\mathrm{CL}$, clamp. 
the endothelium and the tunica adventitia of the GSV wall [Perek 2016; Rousou 2009]. The tunica adventitia is injured if it is disrupted from its blood supply, the vasa vasorum [Perek 2016]. Alrawi et al (2001) compared the degree of endothelial damage inflicted by the open and endoscopic techniques of GSV harvesting [Alrawi 2001]. With any of the above surgical techniques, a number of possible factors may cause graft failure or occlusion, including the experience of the surgeon, the surgeon's manual dexterity, the duration of harvesting and anastomoses, the size of the suture employed, the technique of suturing, the size of the vessel operated, and the appropriate instruments [Yaşargil 1967].

Clearly, intraoperative measures are crucial for avoiding graft failure [Woodward 2016]. Significant differences are found in the results of surgeons using the same technique for bypass grafting. Surgeons (and sometimes young residents or surgical assistants) harvesting the GSV segments were reported to cause microscopic or macroscopic local endothelial disruptions even with the use of no-touch or endoscopic techniques [Perek 2016; Rousou 2009]. Attempting the anastomosis of a vein is not advisable until one is entirely satisfied with one's ability to perform the anastomosis of arteries [Acland 1980].

The vein system is generally highly adaptable to an increase in blood volume through dilatation and a change in geometry. Therefore, the distinction between normal veins and varicose veins is not always sharp, although some histologic differences between veins that are considered to be normal and varicose veins have been reported [Pounds 2014]. A normal, relaxed vein is capable of doubling in volume for a $0-10 \mathrm{mmHg}$ increase in transmural pressure [Sumpio 2014]. All veins have thinner walls than their matching arteries and have valves, unlike arteries; therefore, a clear crossroad point for the occurrence of chronic venous insufficiency and varicose veins is not yet known, nor is the etiology of varicose veins [Pounds 2014; Sumpio 2014]. There is still a lack of data on the linear elastic and non-linear hyperelastic mechanical properties of the varicose saphenous vein under mechanical loading, which would be helpful in understanding the changes in blood's hemodynamic properties according to alterations in vessel structure [Karimi 2015]. This information is very significant because the mechanical conduct of the coronary artery is entirely non-linear. Karimi et al studied both healthy and varicose veins obtained during surgery or autopsy from 7 individuals and found that there was a weakness in the mechanical strength of the varicose saphenous vein [Karimi 2015]. Although not well-established, recent evidence suggests that varicose veins result from weakness of the vein wall and subsequent venous valve incompetence, including a decrease in leaflet height and width, and sometimes total disappearance [Pounds 2014; Sumpio 2014].

Whereas venous anatomy is relatively ignored and not well researched, it is critical to understand the vein wall and venous system, including the so-called insufficient or varicose veins, because of the frequent use of veins in bypass surgery. Varicose saphenous veins were reported to have degradation of the elastic lamella, a relative abundance of collagen fibers, and a decrease of elastic fibers [Pounds 2014; Sumpio 2014].
However, an abundance of collagen fibers and a paucity of elastic fibers in comparison to arteries are general features of all veins, which aid their compliance and capacitance in contrast to the resistance of arteries. This disparity from arteries is particularly prominent in large caliber veins such as the GSV. All these relative differences seem to be a result of adaptation of the veins to accommodate an increase of blood volume, which also differs from one healthy person to the next and is not specific to varicose veins alone.

Therefore, despite the above-mentioned histological modifications and a relative weakness in wall strength, varicose veins would be expected to behave biologically similarly to non-varicose veins. Furthermore, the similarities between normal and varicose veins regarding the preservation of endothelial and adventitial cells and morphology make varicose veins an alternative in the absence of a suitable graft [Kurdal 2009]. Varicose vein grafts offer similar results to normal veins and could provide well-protected endothelial and medial connective tissues [Kurdal 2009]. Therefore, varicose veins have been used successfully as bypass conduit in some cases [Moritz 1993; Neufang 2018]. However, in these cases, it is advised that an external vein support, such as polytetrafluoroethylene prostheses, be used [Neufang 2018]. Neufang et al reported that these grafts also proved good long-term graft patency with a low rate of vein graft degeneration in infrainguinal bypass surgery [Neufang 2018].

A limitation of our study could be a lack of comparison with samples from non-varicose, healthy vein segments to standardize the vessel diameters and histomorphometric properties of the varicose veins. However, harvesting of any healthy veins for experimental purposes is unacceptable because of ethical reasons. The number of patients included in this research was small; however, the study compares different forces on the vein from the same patient and the statistical analysis proved to be significant. The ballooning pressure in this study could be considered to be too high to occur in actual surgery; however, we replicated previously published studies done in laboratory settings. Although we demonstrate venous damage is caused by either internal or external manipulation, no direct correlation can be made between the damage done during harvest and the destiny of the venous graft after bypass surgery. A comparison of the effects of simultaneous, short-duration, externally squeezing and internally distending forces on the same segment of exvivo human GSV is most unlikely in a clinical setting.

Any information regarding the effect of pressure forces applied to the human saphenous venous wall for a short time, either internally or externally, is of great interest, particularly when this vessel is used as a bypass conduit. In our study, all of the clamp-applied, balloon-applied, and control rings of veins were obtained from the same vein segment of the same patient. The results of this study demonstrate that both internal and external pressure forces applied to the human saphenous venous wall can be equally hazardous. These effects of externally squeezing or internally distending forces on the exvivo human GSV suggest that even relatively mild distending or stretching forces during GSV harvesting in an actual surgery could easily injure the vein and subsequently lead to 
the failure of the graft in the early or late period after surgery. Because varicose veins adapt to larger blood volume and have more collagen, they may be more resistant to internal pressures than normal veins. However, their thinner walls may make varicose veins more susceptible to external pressures than normal veins. A comparative study in the future, although difficult to design, could shed light on these issues.

\section{Conclusion}

Pressure forces applied to the human saphenous venous wall for a short time, either internally or externally, have harmful effects on the vein wall. To avoid graft failure, intraoperative measures are crucial when using endoluminal balloon or external clamp techniques.

\section{The authors thank Mrs. Ann Hazinedar for her belp in proofreading.}

\section{REFERENCES}

Acland RD. 1980. Microsurgery practice manual. St Louis: The C.V. Mosby Company. pp 65-69.

Alrawi SJ, Balaya F, Raju R, Cunningham Jr J, Acinapura A. 2001. A comparative study of endothelial cell injury during open and endoscopic saphenectomy: an electron microscopic evaluation. Heart Surg Forum 4:120-7.

Babin-Ebell J, Gimpel-Henning K, Sievers HH, Scharfschwerdt M. 2010. Influence of clamp duration and pressure on endothelial damage in aortic cross-clamping. Interact Cardiovasc Thorac Surg 10:168-71.

Bourassa MG, Campeau L, Lesperance J, Grondin CM. 1982. Changes in grafts and coronary arteries after saphenous vein aortocoronary bypass surgery: results at repeat angiography. Circulation 65:90-7.

Cook RC, Crowley CM, Hayden R, et al. 2004. Traction injury during minimally invasive harvesting of the saphenous vein is associated with impaired endothelial function. J Thorac Cardiovasc Surg 127:65-71.

Davies M, Hagen P-O. 2011. Reprinted article: Pathophysiology of vein graft failure: a review. Eu J Vasc Endovasc Surg 42:S19-29.

Donaldson MC, Mannick JA, Whittemore AD. 1992. Causes of primary graft failure after in situ saphenous vein bypass grafting. J Vasc Surg 15:113-18; discussion 118-120.

Dreifaldt M, Mannion JD, Bodin L, et al. 2013. The no-touch saphenous vein as the preferred second conduit for coronary artery bypass grafting. Ann Thorac Surg 96:105-11.

Eddleman C, Getch C, Bendok B, Batjer H. 2010. Saphenous vein grafts for high-flow cerebral revascularization. In Abdulrauf SI (ed): Cerebral Revascularization: Techniques in Extracranial-to-Intracranial Bypass Surgery. Elsevier Health Sciences, Philadelphia, pp 125-8.

Gabeler EE, Gussenhoven EJ, van Urk H, et al. 2002. A comparison of balloon injury models of endovascular lesions in rat arteries. BMC cardiovascular disorders Sep 27;2:16.

Hashmi SF, Krishnamoorthy B, Critchley WR, et al. 2015. Histological and immunohistochemical evaluation of human saphenous vein harvested by endoscopic and open conventional methods. Interact Cardiovasc Thorac Surg 20:178-85.

Horvath KD, Gray D, Benton L, Hill J, Swanstrom LL. 1998. Operative outcomes of minimally invasive saphenous vein harvest. Am J Surg $175: 391-5$

Johnson JL, van Eys GJ, Angelini GD, George SJ. 2001. Injury induces dedifferentiation of smooth muscle cells and increased matrix-degrading metalloproteinase activity in human saphenous vein. Arterioscler Thromb Vasc Biol 21:1146-51.

Kaplan S, Bisleri G, Kılınç K, Çobanoğlu A, Öz MC. 2013. Effects of harvesting technique on endothelial inflammation and nitric oxide production in saphenous vein grafts. Türk Göğüs Kalp Damar Cerrahisi Dergisi 21:31-6.

Karabulut H, Karabulut O, Arbak S, et al. 1998. Endothelial damage in preparation of saphenous vein used as graft in coronary bypass surgery: Light and electron microscopic examination. [Koroner Bypass Cerrahisinde Greft Olarak Kullanılan Safen Veninin Hazırlanmasında endotel Hasarı: Işı1k ve Elektron Mikroskopik Inceleme]. Türk Kardiyol Dern Arş 26:416-424 [Turkish].

Karimi A, Navidbakhsh M, Kudo S. 2015. A comparative study on the mechanical properties of the healthy and varicose human saphenous vein under uniaxial loading. J Med Eng Technol 39:490-7.

Kopjar T, Dashwood MR. 2016. Endoscopic versus "no-touch" saphenous vein harvesting for coronary artery bypass grafting: a trade-off between wound healing and graft patency. Angiology 67:121-32.

Krayenbühl H. 1977. Comments on the history of external-internal anastomosis for cerebral ischemia. In Schmiedek P, Gratzl O, Spetzler RF. Microsurgery for Stroke. Springer-Verlag, New York, pp 3-7.

Kurdal AT, Ustundag N, Guven A, et al. 2009. Protection of saphenous vein graft from arterial pressure: an experimental study. Thorac Cardiovasc Surg 57:333-8.

Kwok MWT, Lau RHL, Underwood MJ. 2016. Coronary artery bypass surgery: on-pump and off-pump techniques. In Țintoiu IC, Underwood MJ, Cook SP, Kitabata H, Abbas A (eds): Coronary Graft Failure: State of the Art. Springer International Publishing, Switzerland.

Manship LL, Moore WM, Bynoe R, Bunt TJ. 1985. Differential endothelial injury caused by vascular clamps and vessel loops. II. Atherosclerotic vessels. Am Surg 51:401-6.

Meng X, Mavromatis K, Galis ZS. 1999. Mechanical stretching of human saphenous vein grafts induces expression and activation of matrix-degrading enzymes associated with vascular tissue injury and repair. Experimental and molecular pathology 66:227-37.

Moritz A, Grabenwoger F, Raderer F, et al. 1993. Use of varicose veins as arterial bypass grafts. Cardiovasc Surg 1:508-12.

Neufang A, Espinola-Klein C, Savvidis S, et al. 2018. External polytetrafluoroethylene reinforcement of varicose autologous vein grafts in peripheral bypass surgery produces durable bypass function. J Vasc Surg 67:1778-87.

Osgood MJ, Hocking KM, Voskresensky IV, et al. 2014. Surgical vein graft preparation promotes cellular dysfunction, oxidative stress, and intimal hyperplasia in human saphenous vein. J Vasc Surg 60:202-11.

Perek B. 2016. Early CABG Failure. In Ţintoiu I, Underwood M, Cook S, Kitabata H, Abbas A (eds): Coronary Graft Failure: State of the Art. Springer International Publishing, Switzerland, pp 131-8.

Pilmane M, Ozolina L, Ābola Z, et al. 2011. Growth factors, their receptors, neuropeptide-containing innervation, and matrix metalloproteinases in the proximal and distal ends of the esophagus in children with esophageal atresia. Medicina 47:453.

Pounds L, Killewich L. 2014. Venous physiology. In Cronenwett J, 
Johnston K (eds): Rutherford's vascular surgery. Saunders Elsevier, Philadelphia, pp 150-62.

Rousou LJ, Taylor KB, Lu X-G, et al. 2009. Saphenous vein conduits harvested by endoscopic technique exhibit structural and functional damage. Ann Thorac Surg 87:62-70.

Sayers RD, Watt PA, Muller S, Bell PR, Thurston H. 1992. Endothelial cell injury secondary to surgical preparation of reversed and in situ saphenous vein bypass grafts. Eur J Vasc Surg 6:354-61

Souza DS, Dashwood MR, Tsui JC, et al. 2002. Improved patency in vein grafts harvested with surrounding tissue: results of a randomized study using three harvesting techniques. Ann Thorac Surg 73:1189-95.

Stone D, Walsh D. 2014. Local complications: graft thrombosis. In Cronenwett J, Johnston K (eds): Rutherford's vascular surgery. 8th edn. Saunders Elsevier, Philadelphia, pp 683-703.

Sumpio B, Chin J. 2014. Vessel wall biology. In Cronenwett J, Johnston K (eds): Rutherford's vascular surgery. Saunders Elsevier, Philadelphia, pp 34-48.

Tajima H, Araki Y, Izumi T, et al. 2017. Coiling of a ruptured large internal carotid artery aneurysm via extracranial-intracranial saphenous vein bypass graft just after proximal ligation of the internal carotid artery. World neurosurgery 98:879. e871-79.
Wali MA, Dewan M, Eid RA. 2003. Histopathological changes in the wall of varicose veins. Int Angiol 22:188-93.

Wise ES, Hocking KM, Luo W, et al. 2016. Traditional graft preparation decreases physiologic responses, diminishes viscoelasticity, and reduces cellular viability of the conduit: A porcine saphenous vein model. Vasc Med 21:413-21.

Wise ES, Hocking KM, Evans BC, et al. 2017. Unregulated saphenous vein graft distension decreases tissue viscoelasticity. Perfusion 32:489-94.

Woodward LC, Antoniades C, Taggart DP. 2016. Intraoperative vein graft preservation: What is the solution? Ann Thoracic Surg 102:1736-46.

World Medical Association. 2013. World Medical Association Declaration of Helsinki: ethical principles for medical research involving human subjects. Jama 310:2191.

Yaşargil M. 1967. Experimental small vessel surgery in the dog including patching and grafting of cerebral vessels and the formation of functional extra-intracranial shunts. In Donaghy R, Yaşargil M (eds): Micro-Vascular Surgery. Georg Thieme Verlag, Stuttgart, pp 87-126.

Yaşargil M, Krayenbuhl H, Jacobson J. 1970. Microsurgical arterial reconstruction. Surgery 67:221-33. 